\title{
Surface chemistry of hydrazine on $\operatorname{Pt}(111)$
}

\author{
Diann J. Alberas, J. Kiss ', Z.-M. Liu and J.M. White \\ Department of Chemistry and Biochemistry, University of Texas at Austin, Austin, TX 78712, USA
}

Received 27 January 1992; accepted for publication 4 July 1992

\begin{abstract}
The thermal decomposition of hydrazine, $\mathrm{N}_{2} \mathrm{H}_{4}$, adsorbed on a $\mathrm{Pt}(111)$ surface at $60 \mathrm{~K}$ has been investigated by temperature programmed desorption (TPD), high resolution electron energy loss spectroscopy (HREELS), X-ray photoelectron spectroscopy (XPS), ultraviolet photoelectron spectroscopy (UPS), and temperature programmed secondary ion mass spectroscopy (TPSIMS). Condensed multilayer and chemisorbed states of hydrazine can be distinguished. Submonolayer hydrazine coverages start to decomposc betwecn 150 and $200 \mathrm{~K}$ by dissociation of $\mathrm{N}-\mathrm{H}$, not $\mathrm{N}-\mathrm{N}$, bonds. In TPD, $\mathrm{H}_{2}, \mathrm{NH}_{3}$, and $\mathrm{N}_{2}$ all peak near $310 \mathrm{~K}$. $\mathrm{N}_{2}$ and $\mathrm{NH}_{3}$ desorb in processes limited by the rates of the reactions forming them. $\mathrm{N}_{2}$ is formed by an intramolecular process. No nitrogen containing species are detected above $400 \mathrm{~K}$ in HREELS or XPS. Depending on the surface coverage and temperature, dihydrogen desorption is probably limited by both the recombination rate and the rate of $\mathrm{N}-\mathrm{H}$ cleavage. We propose that: (1) the low temperature $\mathrm{N}-\mathrm{H}$ bond cleavage and the retention of $\mathrm{N}-\mathrm{N}$ bonds are facilitated by the chemisorption of $\mathrm{N}_{2} \mathrm{H}_{4}$ through both nitrogen atoms, and (2) relative to the $\mathrm{N}$-metal bond, the $\mathrm{H}$-metal bond is stronger on Pt(111). As a result, the barrier to $\mathrm{N}-\mathrm{H}$ cleavage is lowered much more than the barrier to $\mathrm{N}-\mathrm{N}$ cleavage, and the former is preferred.
\end{abstract}

\section{Introduction}

The adsorption and decomposition of hydrazine has been studied on several metal surfaces [1-14]. According to these reports, decomposition can occur by a number of different paths, depending on the metal. In one path, the $\mathrm{N}-\mathrm{N}$ bond breaks first, leaving $\mathrm{NH}_{2}$ species on the surface. These typically decompose to $\mathrm{N}$ and $\mathrm{H}$, which, upon thermal activation, recombine to desorb $\mathrm{N}_{2}$ and $\mathrm{H}_{2}$. In a second path, the $\mathrm{NH}_{2}$ species react with $\mathrm{H}$ to desorb $\mathrm{NH}_{3}$. In a third path, the $\mathrm{N}-\mathrm{H}$ bonds break first, forming species such as $\mathrm{N}_{2} \mathrm{H}_{3}, \mathrm{~N}_{2} \mathrm{H}_{2}, \mathrm{~N}_{2} \mathrm{H}$, and $\mathrm{N}_{2}$. In this case, $\mathrm{N}_{2}$ is formed intramolecularly, not by $\mathrm{N}$ atom recombination. In a fourth path, hydrazine is directly hydrogenated in a concerted reaction to form ammonia.

Different combinations of these paths have been invoked on different surfaces. For example,

\footnotetext{
1 Permanent address: Reaction Kinetics Research Group of the Hungarian Academy of Sciences, University of Szeged, P.O. Box 105, Szeged, Hungary.
}

on $\mathrm{Fe}(111)$ [4] and $\mathrm{Al}$ foil [6], only the first path is reported. On $\mathrm{Rh}(111)$ [13], all the paths are reported depending on the concentration (coverage) of surface fragments. For example, on $\mathrm{Rh}$ foil [14], at low coverages, the first path is reported, whereas at high coverages, all paths are reported.

In this paper, we report a study of the thermal decomposition of hydrazine on $\mathrm{Pt}(111)$ using a variety of characterization tools to confirm the operative reaction pathways. We find that, at all coverages, decomposition occurs by $\mathrm{N}-\mathrm{H}$, not $\mathrm{N}-\mathrm{N}$, bond breaking. Thus, $\mathrm{N}_{2}$ forms intramolecularly. Ammonia is formed by hydrogenation of $\mathrm{N}_{2} \mathrm{H}_{x}$. A model is proposed in which the strength of the $\mathrm{N}$-metal, as compared to the $\mathrm{N}-\mathrm{N}$ and $\mathrm{N}-\mathrm{H}$ bonds, plays an important role in determining the decomposition path.

\section{Experimental}

The experiments were carried out in two ultra-high $\left((2-3) \times 10^{-10}\right.$ Torr $)$ vacuum cham- 
bers. One chamber was equipped with a low temperature sample holder $(50 \mathrm{~K})$, photoelectron spectroscopy (XPS, UPS) and temperature programmed desorption (TPD) capabilities [15]. The second chamber houses high resolution electron energy loss spectroscopy (HREELS), temperature programmed secondary ion mass spectroscopy (TPSIMS) and Auger electron spectroscopy (AES) facilities, also described elsewhere [16].

HREELS measurements were carried out with a primary beam energy of $6.1 \mathrm{eV}$ and a resolution of $10-12 \mathrm{mV}$ full width at half maximum (FWHM). In XPS measurements, a Mg K $\alpha$ source was used and the analyzer was set for $80 \mathrm{eV}$ pass energy and $0.1 \mathrm{eV}$ step size. TPD and TPSIMS were performed with a temperature ramping rate of 6 and $4.5 \mathrm{~K} / \mathrm{s}$, respectively. An $800 \mathrm{eV} \mathrm{Ar}{ }^{+}$ beam, and a beam flux of $5-30 \mathrm{nA} / \mathrm{cm}^{2}$ was used for SIMS. The temperature was measured with a chromel-alumel thermocouple spotwelded to the back of the sample.

The Pt(111) crystal was cleaned by sputtering with $\mathrm{Ar}^{+}$or $\mathrm{Ne}^{+}$, and by oxidation at $900-1000$ $\mathrm{K}$ in $\mathrm{O}_{2}\left(\sim 5 \times 10^{-8}\right.$ Torr $)$ to remove carbon and annealing to $1200 \mathrm{~K}$ for several minutes to remove residual oxygen. The surface cleanliness was checked by AES and XPS.

Hydrazine (Aldrich Chemical Corporation) was dosed from a glass tube via a capillary doser attached to a variable leak valve. Many cycles of freczing and thawing in liquid nitrogen and $\mathrm{CO}_{2}$ /acetone were used to remove impurities. To minimize hydrazine decomposition before adsorption, the dosing system was carefully preconditioned by exposure to $\mathrm{N}_{2} \mathrm{H}_{4}$. Mass spectral analysis, showing only $\mathrm{N}_{2} \mathrm{H}_{4}$ fragments, was realized after extensive preconditioning. To maintain this condition, we replaced the hydrazine in the dosing manifold between every experiment.

In the chamber containing the low temperature $(50 \mathrm{~K})$ sample holder, the cleanliness of the incoming $\mathrm{N}_{2} \mathrm{H}_{4}$ can be checked by an alternative route. If hydrazine decomposes in the doser, the Pt(111) crystal will be dosed with a multilayer mixture of molecular $\mathrm{H}_{2}, \mathrm{~N}_{2}$, and $\mathrm{NII}_{3}$ gases. These can be distinguished on the basis of their $\mathrm{N}(1 \mathrm{~s})$ XPS signals, e.g., $\mathrm{N}_{2}$ at $402.7 \mathrm{eV}$ [17], and $\mathrm{NH}_{3}$ at $399.9 \mathrm{eV}$ [18]. For the material, purified and dosed as described above, these species were not detectable.

Relative exposures were reproducibly achieved using the following procedure: with the sample turned away from the doser tube, the leak valve was opened to give a predetermined pressure rise at the system ion gauge. To initiate dosing, the sample was turned quickly to intercept the flux from the doser tube. While absolute fluxes to the sample are not known, relative fluxes are reproducible. As outlined below, monolayer coverage is defined in terms of the dose required to observe the onset of multilayer desorption.

\section{Results}

\subsection{TPD}

The TPD products observed after dosing $\mathrm{N}_{2} \mathrm{H}_{4}$ on clean $\mathrm{Pt}(111)$ at $60 \mathrm{~K}$ are $\mathrm{N}_{2} \mathrm{H}_{4}, \mathrm{~N}_{2}, \mathrm{H}_{2}$, and $\mathrm{NH}_{3}$ (figs. 1-4, respectively). For $\mathrm{N}_{2} \mathrm{H}_{4}$ (monitored at $32 \mathrm{amu}$ ), there is no signal at low $\mathrm{N}_{2} \mathrm{H}_{4}$ exposures $(0,10,20 \mathrm{~s})$, i.e., all the hydrazine thermally decomposes. A broad desorption starting at 200 and ending at $300 \mathrm{~K}$ is observed after a $30 \mathrm{~s}$ dose. This peak is saturated at $40 \mathrm{~s}$ and a new peak at $T_{\mathrm{p}}=213 \mathrm{~K}$ appears, which shifts down to $205 \mathrm{~K}$ and saturates at a $60 \mathrm{~s}$ dose. The $205 \mathrm{~K}$ peak is attributed to the desorption of the chemisorbed hydrazine monolaycr; its saturation is taken as the definition of one monolayer. The shape of the hydrazine desorption spectra is similar to that of ammonia on Pt(111) [18]. At low coverages of ammonia, there is also a broad desorption peak at $350 \mathrm{~K}$ attributed to strong charge transfer interactions between the nitrogen lone pair and the surface [18]. We argue against this for the case of hydrazine because unlike ammonia, hydrazine thermally decomposes. Also, there is no other evidence that there are two types of species on the surface. We speculate that the broad higher temperature desorption is attributable to the recombination of $\mathrm{H}$ with $\mathrm{N}_{2} \mathrm{H}_{x}$ to reform hydrazinc. A third low temperature desorption peak at $167 \mathrm{~K}$ is observed at dose times $>40 \mathrm{~s}$. This peak does not saturate and is attributed to the desorption of multilayer $\mathrm{N}_{2} \mathrm{H}_{4}$. 


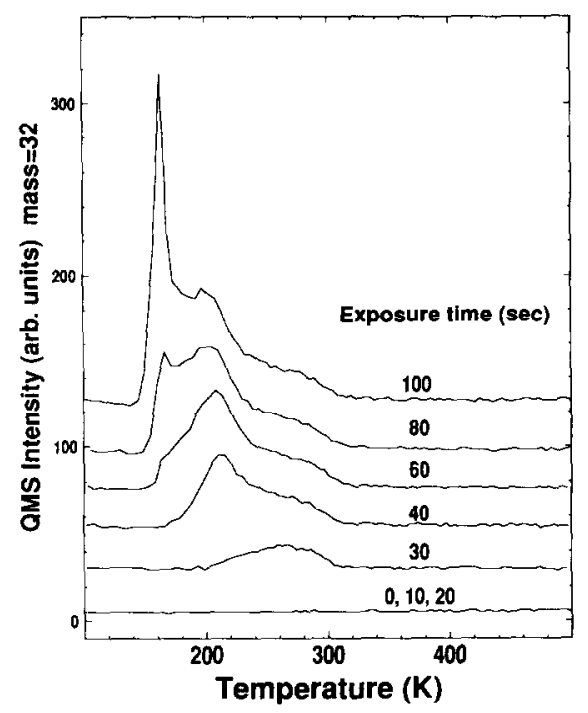

Fig. 1. TPD spectra for various hydrazine exposures on clean $\mathrm{Pt}(111)$. To prepare the system, clean $\mathrm{Pt}(111)$ was exposed to an unknown, but reproducible, flux of $\mathrm{N}_{2} \mathrm{H}_{4}$ from a preconditioned pinhole doser. The flux was chosen to give monolayer coverage in about $60 \mathrm{~s}$ (see curves). The adsorption temperature was $60 \mathrm{~K}$ and the temperature ramp was $6 \mathrm{~K} / \mathrm{s}$. (Same in other TPD figures.)

Comparing the above results to those on other metals, we note the following. On $R h(100)$ [9], the chemisorbed state peaks at 220 and the multilayer at $190 \mathrm{~K}$. On $\mathrm{Rh}$ foil at high coverages, there is a peak at $220 \mathrm{~K}$ [14], and on $\mathrm{Ni}(111)$, multilayer and chemisorbed hydrazine desorption occurs between 150 and $250 \mathrm{~K}$ [8]. Our results for Pt(111) fit nicely into this pattern.

Desorption of $\mathrm{N}_{2}$ (fig. 2) is observed for all doses. It begins at $275 \mathrm{~K}$, ends at $325 \mathrm{~K}$, and reaches a maximum at $310 \mathrm{~K}$. A comparison of 28 and $14 \mathrm{amu}$ (not shown) confirms that the peaks are from $\mathrm{N}_{2}$, not $\mathrm{CO}$. Interestingly, no high temperature desorption of $\mathrm{N}_{2}$, typical of $\mathrm{N}$ atom recombination, is detected. When $\mathrm{N}_{2}$ is dosed at $50 \mathrm{~K}$, previous results show that it desorbs at 60 $\mathrm{K}$ without dissociation $[17,19]$. On the other hand, when atomic nitrogen is dosed at low temperatures $(<200 \mathrm{~K})$, it recombines and desorbs as $\mathrm{N}_{2}$ between 450 and $650 \mathrm{~K}$ [20-22]. We conclude that the $\mathrm{N}_{2}$ observed here is limited by neither desorption of $\mathrm{N}_{2}$ nor by $\mathrm{N}$ atom recombination, i.e., some other reaction limited process controls

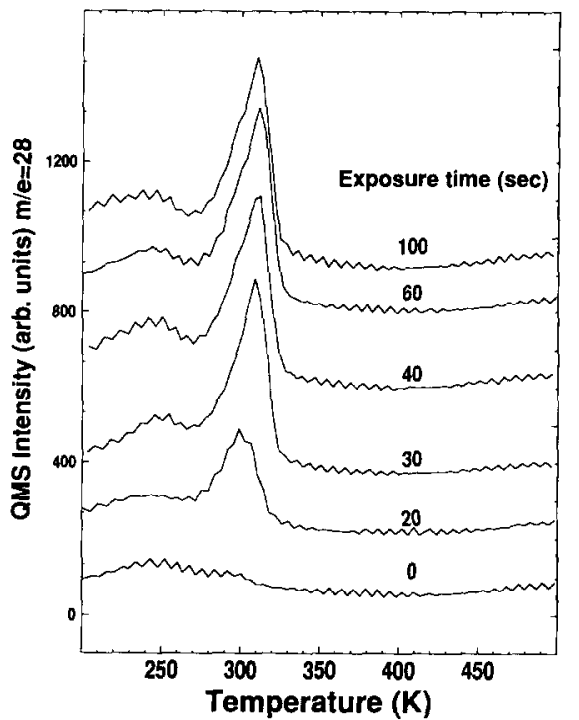

Fig. 2. TPD spectra for $\mathrm{N}_{2}$ from various hydrazine exposures on clean Pl(111). Conditions were identical to those of fig. 1.

the rate. This behavior differs from that on $\operatorname{Ir}(111)$ [5], Rh(111) [13], Rh(100) [9], Ir foil [2], and Rh foil [14] where there is some high temperature recombination of atomic nitrogen.

Desorption of $\mathrm{H}_{2}$ (fig. 3) begins at $270 \mathrm{~K}$, goes through a maximum at $310 \mathrm{~K}$, and ends at $360 \mathrm{~K}$,

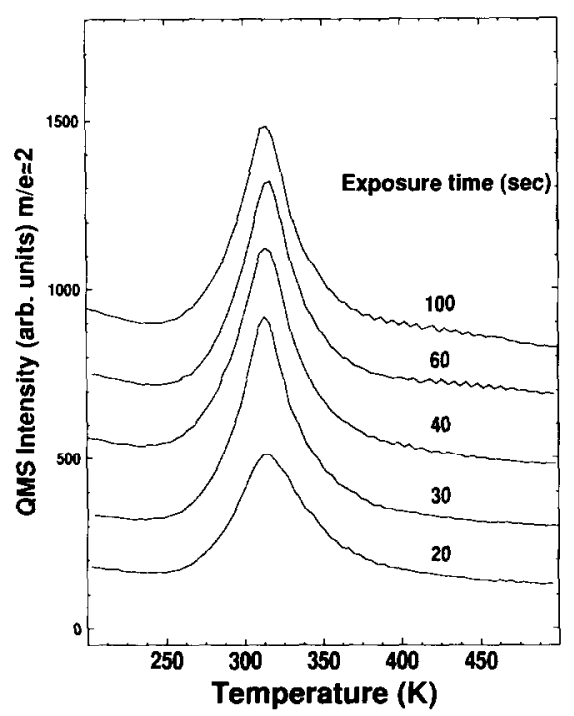

Fig. 3. TPD spectra for $\mathrm{H}_{2}$ from various hydrazine cxposures on clean Pt(111). Conditions were identical to those of fig. 1. 
i.e., tracks $\mathrm{N}_{2}$ desorption reasonably well, but not precisely. In particular, the trailing edge of the $\mathrm{H}_{2}$ desorption extends to higher temperatures. When $\mathrm{H}_{2}$ is dosed on $\mathrm{Pt}(111), \mathrm{H}$ is formed and it recombines and desorbs between 200 and $390 \mathrm{~K}$, depending on the coverage [23]. HREELS and XPS confirm that partial dissociation of parent molecules occurs between 150 and $200 \mathrm{~K}$ (see below). Thus, we cannot conclude whether the $\mathrm{H}_{2}$ peak is controlled by $\mathrm{H}$ atom recombination or by $\mathrm{N}-\mathrm{H}$ dissociation. Likely, each is controlling, but in different coverage-temperature regimes.

There is a sharp $\mathrm{NH}_{3}$ desorption peak at $T_{\mathrm{p}}=$ $310 \mathrm{~K}$ (fig. 4), the shape of which differs from TPD of dosed $\mathrm{NH}_{3}$. Very low coverages of $\mathrm{NH}_{3}$ adsorbed on clean $\mathrm{Pt}(111)$ at $100 \mathrm{~K}$ desorb as a very broad peak above $250 \mathrm{~K}$ [18]. With increasing $\mathrm{NH}_{3}$ coverage, the desorption broadens toward lower temperatures, a new feature attributed to monolayer desorption grows in near $160 \mathrm{~K}$ and the multilayer desorbs at $110 \mathrm{~K}$. We have reproduced these TPD features in our own work. Thus, the $\mathrm{NH}_{3}$ arising from $\mathrm{N}_{2} \mathrm{H}_{4}$ TPD must be the result of a reaction-limited process; we propose the hydrogenation of adsorbed $\mathrm{N}_{2} \mathrm{H}_{x}$ $(x=3,4)$. Later in this paper, we will show that

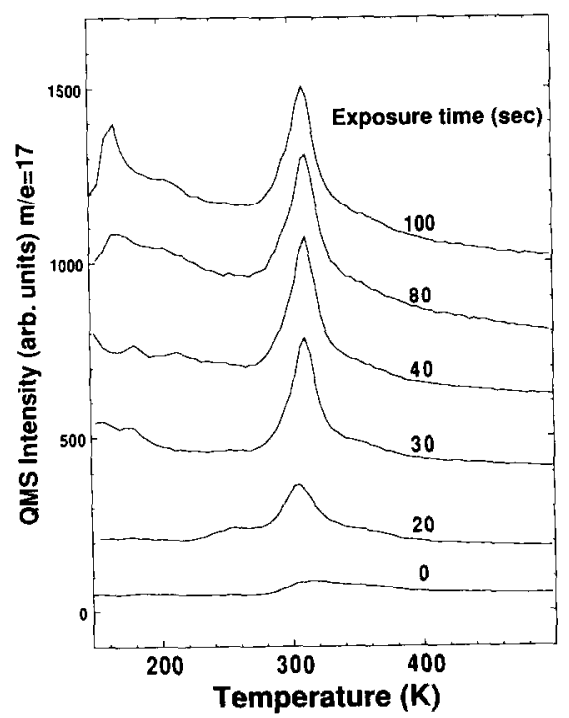

Fig. 4. TPD spectra for $\mathrm{NH}_{3}$ from various hydrazine exposures on clcan $\mathrm{Pt}(111)$. Conditions were identical to those of fig. 1.

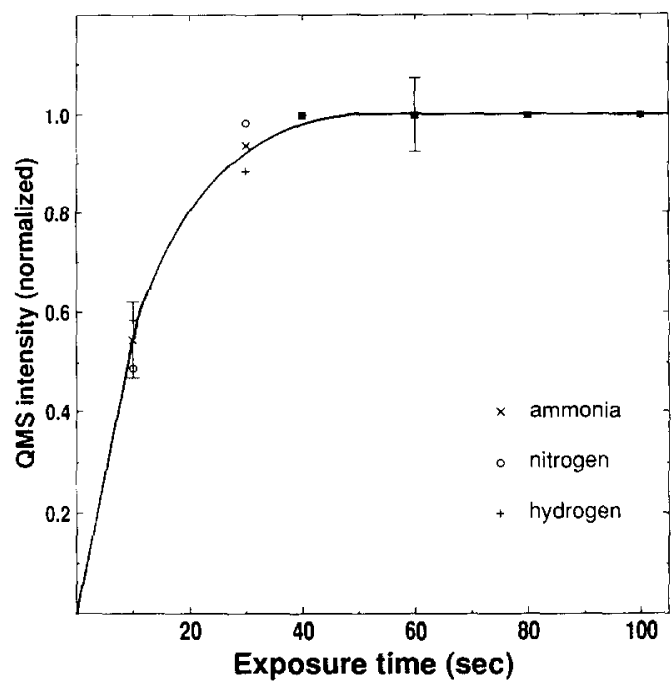

Fig. 5. TPD peak areas, normalized to $100 \mathrm{~s}$ exposure, for $\mathrm{H}_{2}$, $\mathrm{NH}_{3}$, and $\mathrm{N}_{2}$ as a function of exposure time. Data taken from figs. 2-4.

there are no $\mathrm{NH}_{3}$ fragments on the surface, but there are $\mathrm{N}_{2} \mathrm{H}_{x}(x=3,4)$ fragments which lead to the formation of ammonia. The low temperature 17 amu peak in fig. 4 tracks the multilayer hydrazine desorption and is, thus, attributed to fragmentation of hydrazine in the mass spectrometer ion source.

Each of the TPD spectra for $\mathrm{H}_{2}, \mathrm{NH}_{3}$, and $\mathrm{N}_{2}$ has a desorption peak at $310 \mathrm{~K}$ and the peak areas versus exposure time (fig. 5) show a common saturation time of $40 \mathrm{~s}$. We propose (see below) that there is a controlling reaction leading to the nearly simultaneous desorption of products.

We also looked for other desorbing species, particularly diimide $\left(\mathrm{N}_{2} \mathrm{H}_{2}\right)$, which has been observed from $\mathrm{Rh}$ foil over a very broad temperature range beginning at 220 and extending past $400 \mathrm{~K}[14,24]$. Fig. 6 shows 30 and 32 amu spectra from the desorption of $\mathrm{N}_{2} \mathrm{H}_{4}$. The two faithfully track each other, at all coverages, with relative intensities measured for gas-phase $\mathrm{N}_{2} \mathrm{H}_{4}$, suggesting that $\mathrm{N}_{2} \mathrm{H}_{2}^{+}$is a mass spectrometer cracking fragment of $\mathrm{N}_{2} \mathrm{H}_{4}$. While there is cvidence for adsorbed diimide (see below), it does not desorb in detectable amounts. No other species were detected. 


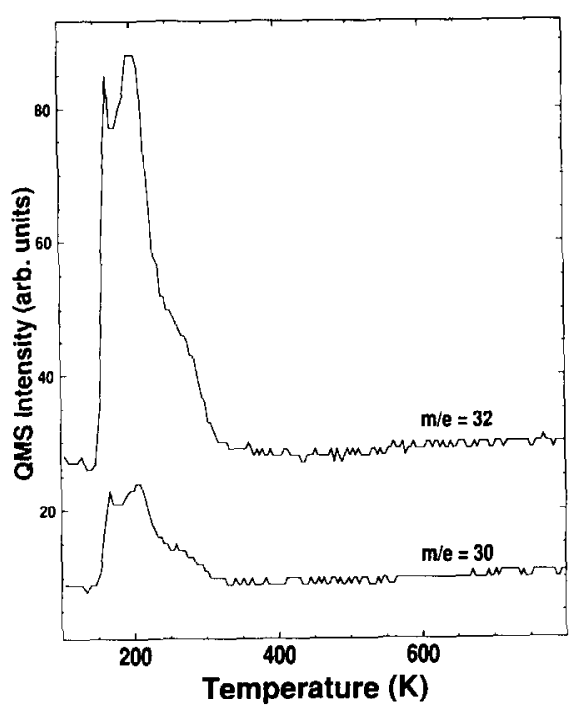

Fig. 6. TPD signals at 30 and 32 amu after adsorption of $\mathrm{N}_{2} \mathrm{H}_{4}$ on clean $\mathrm{Pt}(111)$.

\subsection{HREELS}

To assess the vibrational characteristics of the adsorbed species, we measured, at $106 \mathrm{~K}$, HREELS spectra (fig. 7) of multilayer hydrazine before and after annealing to different temperatures. The data are summarized in table 1 along with comparable data for solid $\mathrm{N}_{2} \mathrm{H}_{4}$ [25], $\mathrm{N}_{2} \mathrm{H}_{4} / \mathrm{Ni}(111)$ [8], and $\mathrm{NH}_{3} / \mathrm{Pt}(111)$ [26].

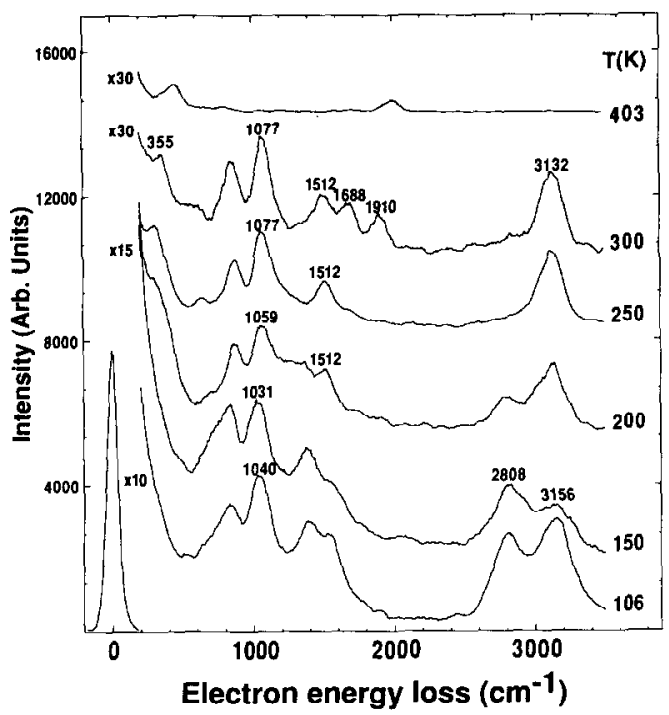

Fig. 7. HREEL spectrum of multilayer $\mathrm{N}_{2} \mathrm{H}_{4}$ adsorbed on clean $\mathrm{Pt}(111)$ at $100 \mathrm{~K}$ (lowest curve) and spectra after brief anneal to indicated temperatures (recooled to take spectra).

The multilayer (106 K) and monolayer (150 K) spectra contain, as anticipated, strong loss peaks assignable to $\mathrm{N}_{2} \mathrm{H}_{4}$ vibrational modes: e.g., 836 $\mathrm{cm}^{-1}, \mathrm{NH}_{2}$ rock; $1040 \mathrm{~cm}^{-1}, \mathrm{~N}-\mathrm{N}$ stretch; 1392 $\mathrm{cm}^{-1}, \mathrm{NH}_{2}$ wag; $1558 \mathrm{~cm}^{-1}, \mathrm{NH}_{2}$ deformation; and $3156 \mathrm{~cm}^{-1}, \mathrm{NH}_{2}$ symmetric stretch (the $\mathrm{NH}_{2}$ asymmetric stretch was not resolved). Another

Table 1

Summary of HREELS data for solid hydrazine on Pt(111) and Ni(111), ammonia on Pt(111) and IR data for solid hydrazine a)

\begin{tabular}{|c|c|c|c|c|c|}
\hline \multicolumn{2}{|c|}{$\mathrm{N}_{2} \mathrm{H}_{4} / \mathrm{Pt}(111)$} & \multirow{2}{*}{$\begin{array}{l}\mathrm{N}_{3} \mathrm{H}_{4} / \mathrm{Ni}(111)^{\mathrm{b})} \\
90 \mathrm{~K}\end{array}$} & \multirow{2}{*}{$\begin{array}{l}\mathrm{NH}_{3} / \mathrm{Pt}(111)^{\mathrm{c})} \\
100 \mathrm{~K}\end{array}$} & \multirow{2}{*}{$\begin{array}{l}\mathrm{N}_{2} \mathrm{H}_{4}{ }^{\mathrm{d})} \\
\text { IR solid }\end{array}$} & \multirow[t]{2}{*}{ Assignment } \\
\hline$\overline{106 \mathrm{~K}}$ & $300 \mathrm{~K}$ & & & & \\
\hline- & 355 & - & 350 & - & $\mathrm{N}-\mathrm{Pt}$ \\
\hline 836 & 855 & 900 & 720 & 884 & $\mathrm{NH}_{2}$ rock \\
\hline 1040 & 1077 & 1070 & - & 1126 & $\mathrm{~N}-\mathrm{N}$ stretch \\
\hline 1392 & e) & 1340 & - & 1304 & $\mathrm{NH}_{2}$ wag \\
\hline- & 1512 & - & - & - & $\mathrm{N}-\mathrm{N}$ stretch, bond order $1<x<3$ \\
\hline 1558 & e) & 1580 & 1630 & 1603 & $\mathrm{NH}_{2}$ deformation \\
\hline- & 1688 & - & - & - & $\mathrm{N}-\mathrm{N}$ stretch, bond order $1<x<3$ \\
\hline- & 1910 & - & - & - & $\mathrm{N}-\mathrm{N}$ stretch, bond order $1<x<3$ \\
\hline 2808 & - & - & - & 3189 & H-bonding \\
\hline 3156 & 3132 & 3150 & 3150 & 3200 & $\mathrm{NH}_{2}$ symmetrical stretch \\
\hline e) & c) & 3300 & 3320 & 3310 & $\mathrm{NH}_{2}$ antisymmetrical stretch \\
\hline
\end{tabular}

\footnotetext{
a) Vibrational frequencies (in $\mathrm{cm}^{-1}$ ).

b) Ref. [8].

c) Ref. [26].

d) Ref. [25].

e) Not resolved.
} 
relatively strong peak $\left(2808 \mathrm{~cm}^{-1}\right)$ was observed at temperatures through $200 \mathrm{~K}$. Tentatively, this peak is assigned to $\mathrm{N}-\mathrm{H}$ stretch modes in hydrogen-bonded hydrazine molecules. For hydrazine in solution, the extent of hydrogen bonding increases with concentration and has a characteristic frequency of $3189 \mathrm{~cm}^{-1}$ [25].

Above $200 \mathrm{~K}$, the major loss peaks are at 355 $\mathrm{cm}^{-1}, \mathrm{Pt}-\mathrm{N}$ stretching; $855 \mathrm{~cm}^{-1}, \mathrm{NH}_{2}$ rocking; $1077 \mathrm{~cm}^{-1}, \mathrm{~N}-\mathrm{N}$ stretching; and $3132 \mathrm{~cm}^{-1}, \mathrm{NH}_{2}$ symmetrical stretching. The persistence of the $\mathrm{N}-\mathrm{N}$ stretching mode (shifting from 1040 to 1077 $\mathrm{cm}^{-1}$ ) is evident through $300 \mathrm{~K}$, and, significantly, its relative intensity increases between 200 and $250 \mathrm{~K}$. To account for the increased intensity, we propose that the adsorbed fragment(s) responsible for this loss change their orientation as the sample is heated. For example, changing the $\mathrm{N}-\mathrm{N}$ bond orientation from a parallel to a tilted (up to perpendicular) orientation to the surface, probably accompanied by $\mathrm{N}-\mathrm{H}$ cleavage, would increase the cross section for this vibrational excitation.

A new peak at $1512 \mathrm{~cm}^{-1}$ appears between 200 and $300 \mathrm{~K}$. We attribute it to adsorbed diimide formed by the loss of hydrogen from hydrazine. From gas-phase UPS spectra, the $\mathrm{N}-\mathrm{N}$ stretch of diimide has an average value of 1556 $\mathrm{cm}^{-1}$ [27]. At $300 \mathrm{~K}$, two additional losses, 1688 and $1910 \mathrm{~cm}^{-1}$, appear and are attributed to other $\mathrm{N}-\mathrm{N}$ bonded species with a bond order greater than 1 and less than 3. This is based on conclusions from a review by Rao and Rao [28], in which increasing vibrational frequencies have increasing bond order, and from comparisons with the $\mathrm{N}-\mathrm{N}$ stretching frequencies of azo compounds which lie between 1572 and $1630 \mathrm{~cm}^{-1}$ [29].

Above $300 \mathrm{~K}$ (fig. 7), no N-Pt stretching frequencies are observed, confirming the complete desorption of all nitrogen-containing species.

\subsection{Photoelectron spectroscopy}

X-ray photoelectron spectra (figs. 8 and 9) were measured to provide more evidence for changes in the surface atomic composition and chemical environment. Low doses of $\mathrm{N}_{2} \mathrm{H}_{4}$ at 60

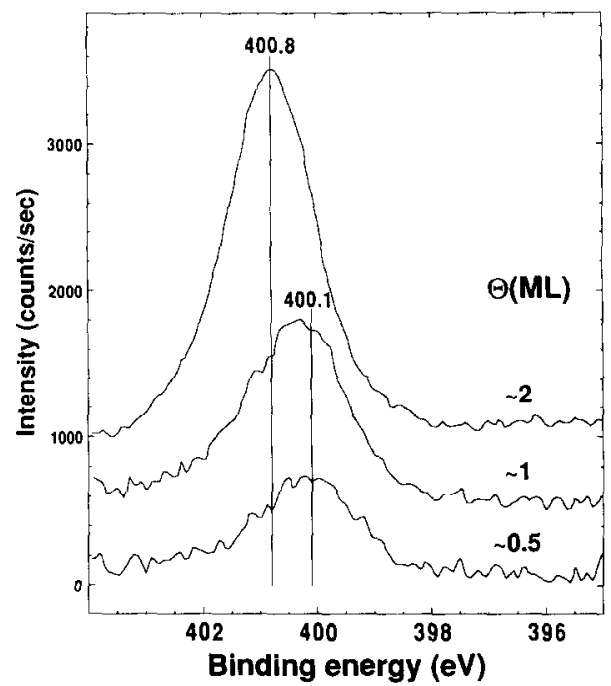

Fig. 8. N(1s) XPS spectra of $0.5,1$, and 2 ML of hydrazine adsorbed $\mathrm{Pt}(111)$ at $60 \mathrm{~K}$. An experimentally determined clean surface background has becn subtracted from each spectrum.

$\mathrm{K}$ give a N(1s) $\mathrm{BE}$ of $400.2 \mathrm{eV}(\mathrm{FWHM}=1.8 \mathrm{eV})$, whereas multilayer spectra (uppermost curve in fig. 8) give a $\mathrm{BE}$ of $400.8 \mathrm{eV}(\mathrm{FWHM}=1.8 \mathrm{eV})$.

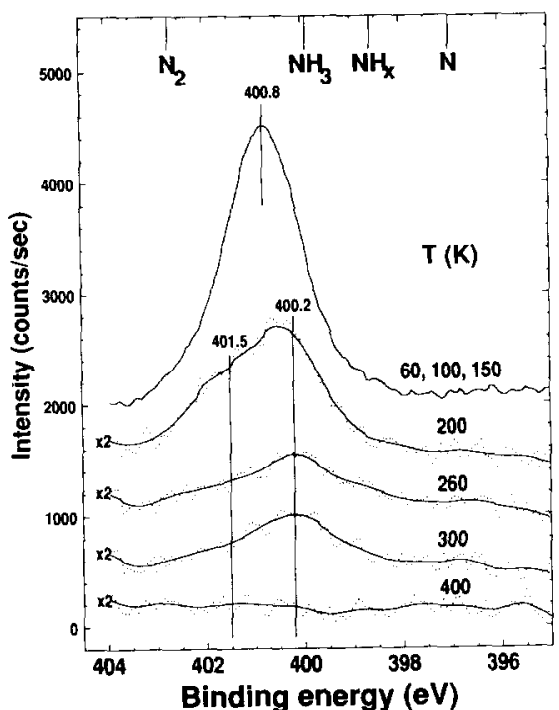

Fig. 9. N(1s) XPS spectra of hydrazine adsorbed on clean $\mathrm{Pt}(111)$ at $55 \mathrm{~K}$ and subsequently heated briefly to the indicated temperature (recooled to take XP spectrum). The dots are the raw data. The solid line is the result of Fourier smoothing. 
These widths are consistent with chemically equivalent nitrogen atoms. Similar binding energy data were determined for monolayer and multilayer $\mathrm{N}_{2} \mathrm{H}_{4}$ on $\mathrm{Fe}(111)$ [4] and on $\mathrm{Rh}(100)$ [9].

Annealing $2 \mathrm{ML}$ of $\mathrm{N}_{2} \mathrm{H}_{4}$, recooling and taking XP spectra leads to the results shown in fig. 9. Importantly, all of the $\mathrm{N}(1 \mathrm{~s})$ signal is gone after a $400 \mathrm{~K}$ anneal, confirming that no significant atomic nitrogen concentration is involved. At low temperatures, from 60 to $150 \mathrm{~K}$, the $\mathrm{N}(1 \mathrm{~s})$ intensity and position do not change, i.e., as expected from TPD, multilayer $\mathrm{N}_{2} \mathrm{H}_{4}$ is preserved. At 200 $\mathrm{K}$, the multilayer has desorbed, and the XP N(1s) intensity is lower and broader, particularly on the higher BE side. This spectrum can be fit with two Gaussian peaks (fig. 10), both with a FWHM of $1.8 \mathrm{eV}$, centered at 400.2 and $401.5 \mathrm{eV}$. The inequivalent nitrogen atoms, indicated here, can be interpreted as the sum of contributions from two species: (1) $\mathrm{N}_{2} \mathrm{H}_{x}$, with one $\mathrm{N}$ strongly bound to $\mathrm{Pt}$ (lower $\mathrm{BE}$ ) and one away from the surface (higher BE) and (2) undissociated $\mathrm{N}_{2} \mathrm{H}_{4}$ with both $\mathrm{N}$ atoms bound to $\mathrm{Pt}$ (lower $\mathrm{BE}$ ). Significantly, the higher BE peak is shifted toward $\mathrm{N}_{2}$ at $402.7 \mathrm{eV}$ [19], not atomic nitrogen at $397 \mathrm{eV}$, as observed in the case of $\mathrm{Fe}(111)$ [4]. An $\mathrm{N}=\mathrm{N}$ species would be consistent with measurements on azomethane adsorbed on $\operatorname{Ag}(111)$ [30]. Thus, XPS is consistent with the HREELS data suggesting that partial decomposition of hydrazine

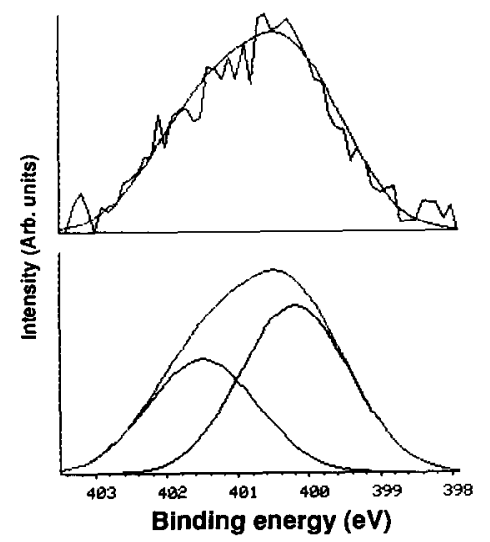

Fig. 10. Deconvolution of the $\mathrm{N}(1 \mathrm{~s})$ peak measured after annealing an $\mathrm{N}_{2} \mathrm{H}_{4}$ multilayer to $200 \mathrm{~K}$. The deconvolution used two peaks with fixed FWHM of $1.8 \mathrm{eV}$.

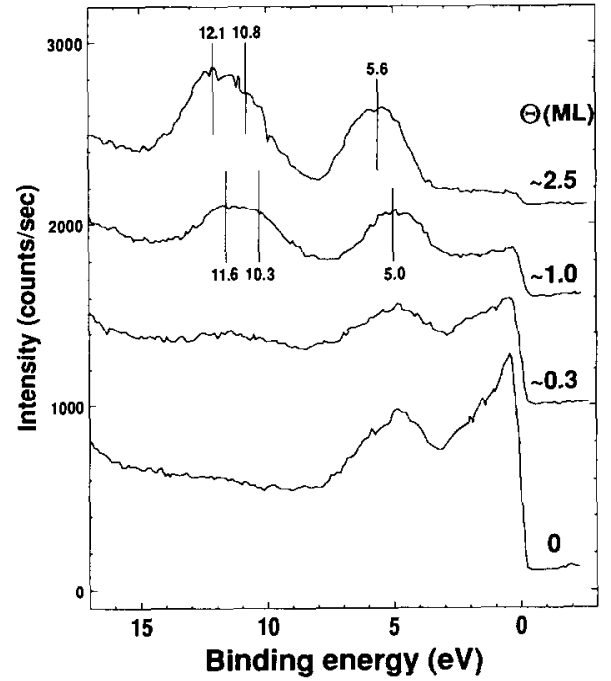

Fig. 11. $\mathrm{He}$ (II) UPS spectra of clean, 0.3, 1, and 2.5 $\mathrm{ML} \mathrm{N}_{2} \mathrm{H}_{4}$ adsorbed on clean $\mathrm{Pt}(111)$. The three features identified are correlated with those of molecular hydrazine (see text).

leads to an $\mathrm{N}_{2} \mathrm{H}_{x}$ species with a bond order greatcr than 1 and less than 3 .

Briefly, we consider other $\mathrm{N}$-containing species. $\mathrm{NH}_{3}$ on Pt(111) has a N(1s) BE at $399.9 \mathrm{eV} \mathrm{[18].}$ $\mathrm{NH}_{x}$ species have N(1s) BE's around $398.6 \mathrm{eV}$ on $\mathrm{Al}$ foil [6] and $\mathrm{Si}(001)$ [31], whereas atomic $\mathrm{N}$ is at $397 \mathrm{eV}$ on Fe [4], Al [32], and $\mathrm{Rh}(100)$ [9]. The absence of these peaks on $\mathrm{Pt}(111)$ underscores the notion that hydrazine decomposes on $\mathrm{Pt}(111)$ by breaking $\mathrm{N}-\mathrm{H}$, not $\mathrm{N}-\mathrm{N}$, bonds, and that $\mathrm{N}_{2}$ forms through an intramolecular process, not through atomic recombination.

Fig. 11 shows $\mathrm{He}$ (II) spectra for three hydrazine coverages. For $1 \mathrm{ML}$, peaks were detected at $5.0,10.3$, and $11.6 \mathrm{eV}$ relative to the Fermi level. These are identified with the following molecular orbitals: $\mathrm{n}_{\mathrm{N}}(4.82,5.12 \mathrm{eV}), \sigma_{\mathrm{N}-\mathrm{N}}(10.39 \mathrm{eV})$, and $\pi_{\mathrm{NI}_{2}}(11.72,11.91 \mathrm{eV})$ [33]. Similar UPS peaks were observed on $\mathrm{Fe}(111)$ [4], and $\mathrm{Rh}(100)$ [9]. As expected for decreased final state screening, all the peaks shift to higher $\mathrm{BE}$ (roughly $0.5 \mathrm{eV}$ ) when the coverage increases from monolayer to multilayer.

When the multilayer was heated (not shown), the intensity of all the UTPS features decreased as they did in XPS. As anticipated, there was no 
indication for the retention of a peak at $5.5 \mathrm{eV}$ due to adsorbed $\mathrm{N}$ atoms [34].

\subsection{TPSIMS}

To complement the surface structural data gleaned from XPS and HREELS, we measured temperature programmed secondary ion mass spectra (TPSIMS) under conditions, i.e., static SIMS, where changes due to sputtering were negligible compared to changes due to thermal activation. Fig. 12 shows positive static TPSIM spectra for $17,18,32$, and 33 amu taken during the heating of multilayer hydrazine. For masses 32 and $33\left(\mathrm{~N}_{2} \mathrm{H}_{4}^{1}, \mathrm{~N}_{2} \mathrm{~N}_{5}^{+}\right)$, the spectra start to increase at $125 \mathrm{~K}$ and reach a local maximum at $145 \mathrm{~K}$. This is due to the desorption of the multilayer hydrazine. All four signals maximize at $195 \mathrm{~K}$, decrease sharply to $240 \mathrm{~K}$, and then decrease slowly, ending at $400 \mathrm{~K}$. The persistence of $\mathrm{N}_{2} \mathrm{H}_{4}^{+}$and $\mathrm{N}_{2} \mathrm{~N}_{5}^{+}$signals to above $250 \mathrm{~K}$ lends further support to preservation of $\mathrm{N}-\mathrm{N}$ bonds to high temperatures. The TPSIMS intensities for $\mathrm{NH}^{+}$and $\mathrm{NH}_{2}^{+}$signals at masses 15 and 16 (not shown) were very weak and followed the temporal profiles of the $\mathrm{N}_{2} \mathrm{H}_{4}^{+}$and $\mathrm{N}_{2} \mathrm{~N}_{5}^{+}$peaks. Supporting the XPS and HREELS conclusions that

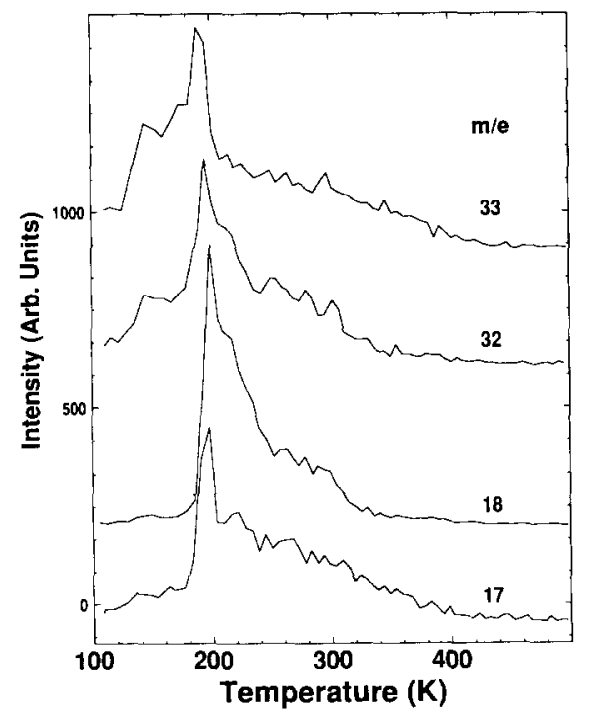

Fig. 12. Positive TPSIMS spectra $(17,18,32$, and $33 \mathrm{amu})$ for multilayer hydrazine adsorbed on clean $\mathrm{Pt}(111)$ at $100 \mathrm{~K}$. The heating rate was $4.5 \mathrm{~K} / \mathrm{s}$.

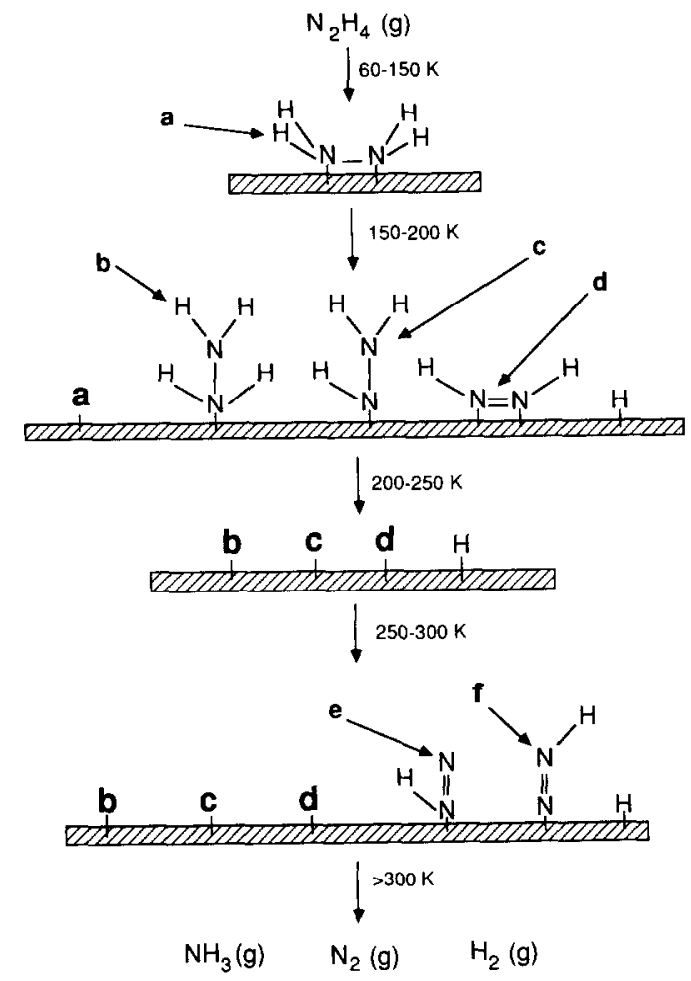

Scheme 1. Schematic of adsorbed intermediates present during thermal processing of chemisorbed hydrazine. Each section lists adsorbed species, thought to be present in significant concentrations. Above $400 \mathrm{~K}$, the surface is clean.

no nitrogen remained above $400 \mathrm{~K}$, we find no SIMS signal for $14 \mathrm{amu}$, or any other $\mathrm{N}$-containing fragment, above $400 \mathrm{~K}$.

The spectra for mass $17\left(\mathrm{NH}_{3}^{+}\right)$and $18\left(\mathrm{NH}_{4}^{+}\right)$ can be attributed either to hydrazine cracking fragments synthesized in the SIMS process or to adsorbed $\mathrm{NH}_{3}$ formed during the decomposition of the parent molecule. Since the temporal profiles for masses 17 and 18 are nearly identical to those for masses 32 and 33, these results are consistent with the proposal made earlier that neither $\mathrm{NH}_{3}$ nor $\mathrm{NH}_{2}$ accumulate, i.e., when $\mathrm{N}-\mathrm{N}$ bond breaking occurs, $\mathrm{NH}_{3}$ desorbs.

\section{Discussion}

To guide the discussion, favored surface structures and relevant temperatures are summarized 
in scheme 1. The features are discussed in more detail below.

\subsection{Structure of adsorbed hydrazine}

Hydrazine is a single bonded nitrogen compound, each nitrogen having $\mathrm{sp}^{3}$ hybridization, and one lone pair on each $\mathbf{N}$. The geometry is analogous to ethane, with a lone pair on each nitrogen replacing one of the hydrogens on each carbon of ethane. Rotation around the $\mathrm{N}-\mathrm{N}$ bond is hindered, the rotational barrier lying between 6 and $10 \mathrm{kcal} / \mathrm{mol}[35,36]$. The equilibrium configuration is gauche because of the large dipole moment of the trans (staggered) conformer and because of the coplaner repulsions in the cis (eclipsed) and half cis (semi-eclipsed) conformers.

Intuitively, the lone pairs on the $\mathrm{N}$ atoms are likely to be involved in bonding to the $\mathrm{Pt}(111)$. Since the N(1s) XPS peak is characteristic of a single type of $\mathrm{N}$ atom $(400.2 \mathrm{eV} \mathrm{BE}$ with a FWHM of $1.8 \mathrm{eV}$ ), we favor the di- $\sigma$ bonded form (species a in scheme 1) in which both $\mathrm{N}$ atoms are bound. This conclusion is consistent with that of Grunze on $\mathrm{Fe}(111)$ [4].

Considering the distances involved, the di- $\sigma$ bonded species is reasonable. The nearestneighbor $\mathrm{Pt}-\mathrm{Pt}$ bond length is $2.77 \AA$. In the cis configuration, we estimate $2.4 \AA$ for the distance between the lone pairs, based on a $\mathrm{N}-\mathrm{N}$ bond length of $1.5 \AA$ [37], an $\mathrm{N}-\mathrm{N}-\mathrm{H}$ bond angle of $108^{\circ}$ [37], and an estimated $\mathrm{N}$-lone pair length of $1.014 \AA$, i.e., the same as the $\mathrm{N}-\mathrm{H}$ bond length [37]. In the gauche configuration, the distance between the lone pairs will be larger. In this way, hydrazine may be bound to the surface through both lone pairs in a configuration between cis and gauche. As the gauche configuration is approached, the hydrogen atoms will move toward the surface, perhaps lowering the barrier to $\mathrm{N}-\mathrm{H}$ cleavage. As we discussed above, hydrogen bonding may also exist at monolayer coverages.

\subsection{Decomposition of chemisorbed hydrazine}

For gaseous hydrazine, the $\mathrm{N}-\mathrm{N}$ bond energy is $38.4 \mathrm{kcal} / \mathrm{mol}$, whereas $\mathrm{N}-\mathrm{H}$ is $93.4 \mathrm{kcal} / \mathrm{mol}$ [38]. Thus, we anticipated, incorrectly, that the
$\mathrm{N}-\mathrm{N}$ bond would break, giving $\mathrm{NH}_{2}$, and that this would dissociate to nitrogen and hydrogen adatoms. Instead, on Pt(111), thermal decomposition proceeds by dissociation of the $\mathrm{N}-\mathrm{H}$ bonds. As outlined below, this may be related to the relatively weak $\mathrm{N}-\mathrm{Pt}$ bond. At the same time, the $\mathrm{Pt}-\mathrm{H}$ bond is quite strong $(62 \mathrm{kcal} / \mathrm{mol}$ [39] derived from the experimental heat of adsorption (19 kcal/mol) of $\mathrm{H}_{2}$ on $\mathrm{Pt}(111)$ [40]).

The relative $\mathrm{N}$-metal bond strengths are related indirectly to the nitrogen recombinative desorption temperatures. On Pt, nitrogen atom recombination (discussed earlier) takes place between 450 and $650 \mathrm{~K}$ [20-22]. This may be compared to the following: $\mathrm{Rh}(111)-670 \mathrm{~K}$ [41]; $\mathrm{Rh}(100)$ - $775 \mathrm{~K}$ [9], and Fe $-800 \mathrm{~K}$ [34]. Therefore, we infer that the relative $\mathrm{N}$-metal bond strengths follow the order: $\mathrm{N}-\mathrm{Pt}<\mathrm{N}-\mathrm{Rh}<$ $\mathrm{N}-\mathrm{Fe}$. Turning to hydrazine decomposition, we note the following: on $\mathrm{Pt}, \mathrm{N}-\mathrm{H}$ bond dissociation dominates; on $\mathrm{Rh}, \mathrm{N}-\mathrm{H}$ and $\mathrm{N}-\mathrm{N}$ bond dissociation are both significant; and on $\mathrm{Fe}, \mathrm{N}-\mathrm{N}$ bond dissociation dominates. The following correlation emerges: the stronger the $\mathrm{N}$-metal bond, the more important $\mathrm{N}-\mathrm{N}$ cleavage becomes.

Upon heating, the hydrazine surface configuration changes (scheme 1). Compared to $150 \mathrm{~K}$, HREELS and XPS spectra have new and/or broader peaks at $200 \mathrm{~K}$. In HREELS, there is a new peak at $1512 \mathrm{~cm}^{-1}$, attributed to diimide (spccies d). In XPS, the monolayer $\mathrm{N}(1 \mathrm{~s})$ can be deconvoluted into two peaks, i.e., chemically inequivalent $\mathbf{N}$ atoms. In addition to residual di- $\sigma$ bound parent, the XPS is consistent with additional $\mathrm{N}_{2} \mathrm{H}_{x}$ species, e.g., rearranged $\mathrm{N}_{2} \mathrm{H}_{4}$, $\mathrm{N}_{2} \mathrm{H}_{3}$ and/or $\mathrm{N}_{2} \mathrm{H}_{2}$ (species b, c and d, respectively, in scheme 1).

In HREELS the $\mathrm{N}-\mathrm{N}$ stretching mode also intensifies and shifts to slightly higher wave numbers between 150 and $200 \mathrm{~K}$. We had expected the intensity of this mode to decrease due to the desorption of the multilayer below $200 \mathrm{~K}$. This increase in intensity is attributed to the loss of a hydrogen from hydrazine forming $\mathrm{N}_{2} \mathrm{H}_{3}$ (species $\mathrm{c}$ in scheme 1). A hydrogen atom shift, forming $\mathrm{NH}-\mathrm{NH}_{3}$ (not shown), cannot be ruled out. The central feature is the reorientation of the $\mathrm{N}-\mathrm{N}$ bond with respect to the surface normal. When 
$\mathbf{N}-\mathbf{N}$ lies parallel to the surface, we anticipate a weak HREELS signal because of image charge screening. For monolayer coverages, "standing up" might occur upon $\mathrm{N}-\mathrm{H}$ cleavage, i.e., $\mathrm{N}-\mathrm{H}$ cleavage leaves most of the $\mathrm{H}$ bound and occupying a site originally occupied by $\mathrm{N}$ from hydrazine. Since, on tungsten films, hydrogen blocks adsorption of hydrazine [42], this $\mathrm{H}$-induced rearrangement is possible. These species are present through $300 \mathrm{~K}$.

The new peaks at 1688 and $1910 \mathrm{~cm}^{-1}$ in HREELS after annealing to $300 \mathrm{~K}$ may be due to other $\mathrm{N}-\mathrm{N}$ bound species which have a bond order $1<x<3$. We tentatively assign these peaks to species $\mathrm{e}$ and $\mathrm{f}$ as shown in scheme 1. Other evidence for the assignments is the shift to higher $\mathrm{BE}$ of the N(1s) XPS, i.e., toward the BE of $\mathrm{N}_{2}$. Both species are also possible intermediates in the intramolecular $\mathrm{N}_{2}$ formation, i.e., loss of hydrogen and subsequent changes in the hybridization produces $\mathrm{N}_{2}$ which immediately desorbs. The loss of the last hydrogen occurs between 275 and $327 \mathrm{~K}$, the observed range of $\mathrm{N}_{2}$ desorption.

Not all the hydrazine decomposes to form $\mathrm{N}_{2}$; some ammonia desorbs. As discussed above, we believe it is reaction limited. In related work, Wagner and Schmidt [13] observe two reaction limited desorption peaks for mass 17 after hydrazine adsorption on $\mathrm{Rh}(111)$. They attribute the low temperature peak $\left(T_{\mathrm{p}}=180 \mathrm{~K}\right)$ to ammonia from the direct hydrogenation of hydrazine on the surface and the high temperature peak $\left(T_{\mathrm{p}}=\right.$ $250 \mathrm{~K})$ to ammonia from the hydrogenation of $\mathrm{NH}_{2}$ species on the surface. On Pt, there is no evidence for $\mathrm{NH}_{2}$. Therefore, the $\mathrm{NH}_{3}$ desorption peak is thought to be the result of direct hydrogenation of hydrazine or one of its partially dissociated products (e.g., species $\mathrm{c}$ in scheme 1). Tungsten [42], Rh foil [14], and supported iridium [1] substrates behave similarly.

In scheme 1, we have not considered hydrogen bonding interactions. Others have postulated reaction complexes involving two or more $\mathrm{N}_{2} \mathrm{H}_{4}$ molecules. For example, Wood and Wise [2], have suggested a mechanism, originally postulated by Szwarc [43], by which the nitrogens of $\mathrm{N}_{2} \mathrm{H}_{4}$ and $\mathrm{N}_{2} \mathrm{H}_{2}$ species are bound in a square configuration and react to form $\mathrm{N}_{2}$ and $\mathrm{NH}_{3}$ by the trans- fer of hydrogen. This would allow for the simultaneous release of $\mathrm{N}_{2}$ and $\mathrm{NH}_{3}$. However, it may be only coincidental that $\mathrm{N}_{2}, \mathrm{H}_{2}$ and $\mathrm{NH}_{3}$ all desorb at the same temperature since there are cases where reaction-limited desorption of $\mathrm{N}_{2}$ formed intramolecularly, and $\mathrm{NH}_{3}$ formed by direct hydrogenation of hydrazine are observed at different temperatures [8]. There are also cases, similar to that on $\operatorname{Pt}(111)$, where $\mathrm{N}_{2}$ and $\mathrm{NH}_{3}$ desorb simultaneously $[1,5,14]$.

\section{Conclusions}

The work reported here can be summarized as follows:

(1) Hydrazine, $\mathrm{N}_{2} \mathrm{H}_{4}$, adsorbs molecularly on $\mathrm{Pt}(111)$ at $60 \mathrm{~K}$. Both nitrogen lone pairs are involved.

(2) Hydrazine desorption occurs in three peaks, a multilayer peak at $165 \mathrm{~K}$, and monolayer peaks at 211 and $270 \mathrm{~K}$. The $270 \mathrm{~K}$ peak likely involves hydrogenation of partially decomposed hydrazine. Three reaction products are found in TPD $-\mathrm{N}_{2}, \mathrm{NH}_{3}$ and $\mathrm{H}_{2}-$ all desorbing near $310 \mathrm{~K}$.

(3) Thermal decomposition of hydrazine starts between 150 and $200 \mathrm{~K}$ and occurs only for those molecules bound to the surface. $\mathrm{N}-\mathrm{H}$, not $\mathrm{N}-\mathrm{N}$, bonds break and $\mathrm{N}_{2}$ forms, and desorbs near 310 $\mathrm{K}$, through an intramolecular process. Chemisorption of hydrazine through both nitrogen atoms helps retain the $\mathrm{N}-\mathrm{N}$ bond and facilitate low temperature $\mathrm{N}-\mathrm{H}$ bond cleavage. The stronger $\mathrm{H}-\mathrm{Pt}$ bond, compared to the $\mathrm{N}-\mathrm{Pt}$ bond, also contributes to preferential cleavage of $\mathrm{N}-\mathrm{H}$ bonds.

(4) Ammonia is also detected and is attributed to the direct hydrogenation of either $\mathrm{N}_{2} \mathrm{H}_{4}$ or $\mathrm{N}_{2} \mathrm{H}_{3}$ species using hydrogen from decomposed hydrazine.

\section{Acknowledgement}

This research was supported in part by the US Department of Energy, Office of Basic Energy Sciences. 


\section{References}

[1] J.P. Contour and G. Pannetier, J. Catal. 24 (1972) 434.

[2] B.J. Wood and H. Wise, J. Catal. 39 (1975) 471.

[3] M.H. Matloob and M.W. Roberts, J. Chem. Res. S (1977) 336.

[4] M. Grunze, Surf. Sci. 81 (1979) 603.

[5] H.H. Sawin and R.P. Merrill, J. Chem. Phys. 73 (1980) 996.

[6] D.W. Johnson and M.W. Roberts, J Electron Spectrosc. Relat. Phenom. 19 (1980) 185.

[7] M. Kiskinova and D.W. Goodman, Surf. Sci. 109 (1981) L555.

[8] J.L. Gland, G.B. Fisher and G.E. Mitchell, Chem. Phys. Lett. 119 (1985) 89.

[9] W.M. Daniel and J.M. White, Surf. Sci. 171 (1986) 289.

[10] D.M. Littrell and B.J. Tatarchuk, J. Vac. Sci. Technol. A 4 (1986) 1608.

[11] D.M. Littrell, D.H. Bowers and B.J. Tatarchuk, J. Chem. Soc. Faraday Trans. 1, 83 (1987) 3271.

[12] G.A. Papapolymerou and L.D. Schmidt, Langmuir 3 (1987) 1098.

[13] M.L. Wagner and L.D. Schmidt, Surf. Sci. 257 (1991) 113.

[14] J. Prasad and J.L. Gland, Langmuir 7 (1991) 722.

[15] S.K. Jo, J. Kiss, J.A. Polanco and J.M. White, Surf. Sci. 253 (1991) 233.

[16] G.E. Mitchell, P.L. Radloff, C.M. Greenlief, M.A. Henderson and J.M. White, Surf. Sci. 183 (1987) 403.

[17] J. Kiss, S.K. Jo and J.M. White, to be published.

[18] G.B. Fisher, Chem. Phys. Lett. 79 (1981) 452.

[19] J. Kiss, D. Lennon, S.K. Jo and J.M. White, J. Phys. Chem. 95 (1991) 8054.

[20] K. Schwaha and E. Bechtold, Surf. Sci. 66 (1977) 383.

[21] J. Kiss, A. Berko and F. Solymosi, in: Proc. 8th Int. Vacuum Congr. and 4th Int. Conf. on Solid Surfaces, Eds. D.A. Degrass and M. Costa (Societe Francaise du Vide, Cannes, France, 1980) p. 521.

[22] F. Solymosi and J. Kiss, Surf. Sci. 108 (1981) 641.
[23] K. Christmann, G. Ertl and T. Pignet, Surf. Sci. 54 (1976) 365.

[24] J. Prasad and J.L. Gland, J. Am. Chem. Soc. 113 (1991) 1577.

[25] J.R. Durig, S.F. Bush and E.E. Mercer, J. Chem. Phys. 44 (1966) 4238.

[26] B.A. Sexton and G.E. Mitchell, Surf. Sci. 99 (1980) 523.

[27] D.C. Frost, S.T. Lee, C.A. McDowell and N.P.C. Westwood, J. Chem. Phys. 64 (1976) 4719.

[28] C.N.R. Rao and G.R. Rao, Surf. Sci. Rep. 13 (1991) 221.

[29] CRC Atlas of Spectral Data and Physical Constants for Organic Compounds, Ed. J. G. Grassclli (CRC Press, Cleveland, $\mathrm{OH}, 1973$ ).

[30] M.E. Castro, L.A. Pressley and J.M. White, Surf. Sci. 256 (1991) 227.

[31] J.L. Bischoff, F. Lutz, D. Bolmont and L. Kubler, Surf. Sci. Lett. 248 (1991) L240.

[32] K. Kishi and M.W. Roberts, Surf. Sci. 62 (1977) 252.

[33] W.L. Jorgensen and L. Salem, The Organic Chemist's Book of Molecular Orbitals (Academic Press, New York, 1973).

[34] F. Bozso, G. Ertl, M. Grunze and M. Weiss, J. Catal. 49 (1977) 18

[35] H. Ulich and W. Nespital, Z. Phys. Chem. 16 B (1932) 221.

[36] W. Fresenius and J. Karweil, Z. Phys. Chem. B 44 (1939) 1.

[37] G. Herzberg, Spectra of Diatomic Molecules, 2nd ed. (Van Nostrand, New Jersey, 1957) p. 195.

[38] L. Pauling, The Chemical Bond, A Brief Introduction to Modern Structural Chemistry (Cornell University Press, New York, 1967).

[39] E.A. Carter and B.E. Koel, Surf. Sci. 226 (1990) 339.

[40] B. Poelsema, G. Mechtersheimer and G. Comsa, Surf. Sci. 111 (1981) 519.

[41] J. Kiss and F. Solymosi, Surf. Sci. 135 (1983) 241.

[42] R.C. Cosser and F.C. Tompkins, Trans. Faraday Soc. 67 (1971) 526.

[43] M. Szwarc, Proc. R. Soc. London A 198 (1949) 267. 